\title{
Identification of the Products of Partial Hydrolysis of Silicon Tetrafluoride by Matrix Isolation IR Spectroscopy
}

\author{
P. G. Sennikov ${ }^{a}$, S. K. Ignatov ${ }^{b}$, and O. Schrems ${ }^{c}$ \\ ${ }^{a}$ Institute of Chemistry of High-Purity Substances, Russian Academy of Sciences, ul. Tropinina 49, \\ Nizhni Novgorog, 603950 Russia \\ ${ }^{b}$ Lobachevskii State University, pr. Gagarina 25/3, Nizhni Novgorod, 603950 Russia \\ ${ }^{c}$ Alfred Wegener Institute for Polar and Marine Research, D-27570 Bremerhaven, Germany \\ Received October 15, 2008
}

\begin{abstract}
Matrix isolation Fourier transform IR spectroscopy has been used for studying the products and mechanism of the silicon tetrafluoride reaction with water at various component ratios and reaction durations. Assignment of new bands in the spectrum confirms the earlier assumptions of first the formation of a molecular complex with water and later of trifluorosilanol, which finally condenses to give hexafluorodisiloxane.
\end{abstract}

DOI: $10.1134 / \mathrm{S} 0036023610030198$

In order to meet the rapidly increasing demand of 1 modern industry for amorphous and polycrystalline silicon, new sources and methods of preparation of this material are intensively sought after. Silicon tetrafluoride $\mathrm{SiF}_{4}$ is a promising precursor to silicon as both massive samples and thin layers [1, 2]. This accounts for the growing interest of researchers in developing new methods of analysis of $\mathrm{SiF}_{4}$ and studying its properties $[3,4]$.

The interaction with water (hydrolysis) is among the most important chemical reactions of silicon tetrafluoride. The major product of hydrolysis, stable in the gas phase, is hexafluorodisilixane $\mathrm{Si}_{2} \mathrm{~F}_{6} \mathrm{O}[5,7,8]$. Previously, IR spectroscopy [6] and mass spectrometry [7] showed that an intermediate product of hydrolysis is trifluorosilanol $\mathrm{SiF}_{3} \mathrm{OH}$, which is thermodynamically less favorable and is present in the reaction mixture in small amounts as a kinetic product because of the high activation energy of further transformations [9]. The thermodynamics of formation of these compounds in the gas phase was studied both theoretically by quantum-chemical methods and experimentally by high-resolution IR spectroscopy $[9,10]$. The experimental equilibrium constants were consistent with the calculated values. The change in the concentrations of both products was monitored by observing the change in the intensities of broad featureless bands: the rather strong band at $838 \mathrm{~cm}^{-1}$ due to symmetric $\mathrm{Si}-\mathrm{F}$ stretching vibrations in the $\mathrm{Si}_{2} \mathrm{~F}_{6} \mathrm{O} 2 \mathrm{O}$ molecule (the $\mathrm{Si}-\mathrm{O}$ vibrations in this molecule give rise to the band at about $1200 \mathrm{~cm}^{-1}$ ) and the weak band at $3762 \mathrm{~cm}^{-1}$ due to the $\mathrm{OH}$ bond vibrations in the $\mathrm{SiF}_{3} \mathrm{OH}$ molecule. However, monitoring the change in these bands in time does not answer the question of whether trifluorosilanol is the only and/or dominating $\mathrm{OH}$-contain- ing intermediate and gives no way to reliably interpret the kinetic dependences of the early hydrolysis stages. To solve this problem, one should study the fine structure of the absorption bands at 1000 and $3760 \mathrm{~cm}^{-1}$ and elucidate how their separate components depend on the reaction conditions and duration. This task is however complicated by the fact that, in the region of $1000 \mathrm{~cm}^{-1}$, strong antisymmetric vibrations of the $\mathrm{Si}_{2} \mathrm{~F}_{6} \mathrm{O}$ and $\mathrm{SiF}_{3} \mathrm{OH}$ molecules are overlapped with the extremely strong band $v^{3}\left(1031.4 \mathrm{~cm}^{-1}\right)$ of $\mathrm{SiF}_{4}$ per se [10]. The fine structure of the absorption bands of $\mathrm{Si}_{2} \mathrm{~F}_{6} \mathrm{O}$ and $\mathrm{SiF}_{3} \mathrm{OH}$ molecules at 1000 and $3760 \mathrm{~cm}^{-1}$ cannot be studied even by high-resolution gas-phase IR spectroscopy. Previously [11], we studied the spectra of $\mathrm{SiF}_{4}$ in a solution in liquid argon and krypton at 90 and $160-170 \mathrm{~K}$, respectively. We showed that, in argon, the band $v_{3}$ at $1008.0 \mathrm{~cm}^{-1}$ is split into three components corresponding to silicon-28, -29 , and -30 isotopes. The same spectrum also showed an impurity absorption band at $1015 \mathrm{~cm}^{-1}$, which was presumably assigned to hexafluorodisiloxane. Unfortunately, this experimental method (which is an equilibrium one) cannot be used for studying mixtures of silicon tetrafluoride with water because of the extremely poor solubility of the latter in liquid noble gases. An alternative method for improving the resolution of absorption bands structureless at room temperature and detecting reaction products and unstable intermediates is matrix isolation IR spectroscopy with various gases as lowtemperature matrices. The spectrum of $\mathrm{SiF}_{4}$-water mixtures in an argon matrix at $14 \mathrm{~K}$ and a resolution of $1 \mathrm{~cm}^{-1}$ was studied in [12]. The work focused on identification of weak complexes formed by the fluoride molecule with molecules of oxygen- and nitrogencontaining Lewis bases, including water as the weakest 
base (electron density donor). It was found that the $\mathrm{Si}-\mathrm{F}$ stretches in such a complex give rise to the band at $984 \mathrm{~cm}^{-1}$ and the silicon tetrafluoride band at $1025 \mathrm{~cm}^{-1}$ is split into a large number of narrow lines, no assignment for them having been reported. New bands also appear in the region of water bending vibrations $v_{2}$ $\left(1590 \mathrm{~cm}^{-1}\right)$ and antisymmetric stretching vibrations $v_{3}\left(3700 \mathrm{~cm}^{-1}\right)$. Recently [13], the matrix spectrum ofSiF $_{4}$ in argon, xenon, and nitrogen at $11 \mathrm{~K}$ in the region of the $v_{3}$ band was studied by state-of-the-art FT IR spectroscopy with a resolution of $0.1 \mathrm{~cm}^{-1}$. The spectrum in the argon matrix showed 24 lines due to the ${ }^{28} \mathrm{SiF}_{4},{ }^{29} \mathrm{SiF}_{4}$, and ${ }^{30} \mathrm{SiF}_{4}$. The band at $1029.4 \mathrm{~cm}^{-1}$ was assigned to the $\left({ }^{28} \mathrm{SiF}_{4}\right)_{2}$ dimer. Other regions of the silicon tetrafluoride spectrum were not considered in [13].

In the present work, we study spectral features of the bands in the low-temperature matrix spectra in argon of $\mathrm{SiF}_{4}$-water mixtures in the regions of the $v_{3}$ modes of the fluoride and $v_{2}$ and $v_{1}$ and $v_{3}$ modes of water, as well as in the regions of hexafluorodisiloxane absorption (800-860 and 1160-1200 $\mathrm{cm}^{-1}$ ), in order to elucidate how their intensities and positions respond to the component ratio in a mixture and reaction duration and refine our insight into the mechanism of partial hydrolysis of silicon tetrafluoride.

\section{EXPERIMENTAL}

The IR spectra in an argon matrix were recorded on a setup comprising a Bruker IFS66v FTIR spectrophotometer and a Leybibold ROK 10-300 closed cycle cryostat. With the use of a routine manometric technique, mixtures of $\mathrm{SiF}_{4}$ and $\mathrm{H}_{2} \mathrm{O}$ with various component ratios were prepared directly in the gas line and then mixed with argon in ratios of $1 / 50-1 / 1000$. Matrices were deposited onto an aluminum substrate cooled to $12 \mathrm{~K}$. Spectra were recorded in the range $4250-500 \mathrm{~cm}^{-1}$ with the use of a cooled MCT detector; the resolution was $0.2 \mathrm{~cm}^{-1}$, and up to 400 scans were acquired. Silicon tetrafluoride (Air Liquide), containing less than 10 ppm of carbon monoxide, carbon dioxide, and $\mathrm{C}_{1}-\mathrm{C}_{3}$ hydrocarbons, was used.

\section{RESULTS AND DISCUSSION}

The spectrum of commercially available silicon tetrafluoride usually shows a weak band of the hexafluorodisiloxane impurity $\left(840 \mathrm{~cm}^{-1}\right)$ with a content of $10^{-2}-1$ mol \%. Previously [4], we showed that, under equilibrium conditions in the gas phase, silicon tetrafluoride can also contain on the order of $10^{-3} \mathrm{~mol} \%$ of water. These facts should be taken into account in interpretation of the matrix IR spectrum of initial $\mathrm{SiF}_{4}$. The bands arising from free water (as monomers and dimers) in the $v_{2}$ and $v_{1}$ and $v_{3}$ regions were identified using specially recorded spectra of water, as well as invoking numerous data on the spectra of $\mathrm{H}_{2} \mathrm{O}$ iso- lated in the argon matrix (see, e.g., [14-17] and references therein).

Figure 1 shows portions of the spectrum of initial $\mathrm{SiF}_{4}$ in the argon matrix with a dilution of $1: 1000$ in the region of the $v_{3}$ mode of silicon tetrafluoride and adjacent regions of hexafluorodisiloxane absorption, as well as in the regions of the water $v_{2}$ and $v_{1}$ and $v_{3}$ modes. As is seen, these regions are well resolved. In the range $1010-1030 \mathrm{~cm}^{-1}$ containing the isotope components and the lines of the $\left({ }^{28} \mathrm{SiF}_{4}\right)_{2}$ dimer at $1029.4 \mathrm{~cm}^{-1}$, the positions and relative intensities of the observed lines are consistent with the data in [12, 13]. In the range $950-1000 \mathrm{~cm}^{-1}$, there is a rather strong doublet with maxima at 985.1 (major) and $984.4 \mathrm{~cm}^{-1}$ assigned in [12] to $\mathrm{Si}-\mathrm{F}$ vibrations in the complex with water traces. In the region of the water $v_{2}$ mode, the doublet with maxima at 1592.2 and $1591.7 \mathrm{~cm}^{-1}$, due to water molecules fixed in the $\mathrm{Ar}$ matrix (non-rotating molecules), sharply builds up. Very weak bands emerging at 3641.7 and $3723 \mathrm{~cm}^{-1}$ were assigned in [12] to water vibrations in the complex since no $\mathrm{SiF}_{4}$ interaction products were observed.

The matrix spectra of silicon tetrafluoride with water additions are shown in Figs. 2-4. Figure 2 compares separate portions of the spectra of the following systems: (1) initial $\mathrm{SiF}_{4}$ in argon with a dilution of 1 : $1000\left(\mathrm{Ar} / \mathrm{SiF}_{4}=1000\right)$, (2) the mixture containing excess fluoride with respect to water $\left(\mathrm{Ar} /\left(\mathrm{SiF}_{4}\right.\right.$ 23.8 mbar $+\mathrm{H}_{2} \mathrm{O} 1.3$ mbar) $=1000$, sample 1 ), and (3) the mixture containing equimolar amounts of fluoride and water $\left(\mathrm{Ar} /\left(\mathrm{SiF}_{4} 9.5 \mathrm{mbar}+\mathrm{H}_{2} \mathrm{O} 9.1 \mathrm{mbar}\right)=\right.$ 1000 , sample 2). The intensity of the band at $985.1 \mathrm{~cm}^{-1}$ depends on the water content in a mixture. Significant changes are observed in the range 1020$1010 \mathrm{~cm}^{-1}$ : in both cases, a new band at $1018.8 \mathrm{~cm}^{-1}$ appears, its intensity being maximal at equimolar amounts of the components in a mixture. In the range $1020-1040 \mathrm{~cm}^{-1}$, the intensity of the $\mathrm{SiF}_{4}$ dimer band at $1029.4 \mathrm{~cm}^{-1}$ depends on the water concentration. In going from sample 1 to sample 2, this intensity decreases, while the band at $1027.8 \mathrm{~cm}^{-1}$ builds up. The range $1560-1660 \mathrm{~cm}^{-1}$ contains the lines and bending vibration bands of different water forms. With an increase in the water content, there is an increase in the intensities of the bands lacking in the spectrum of initial silicon tetrafluoride and in the spectrum of water at 1591.8 and $1589.4 \mathrm{~cm}^{-1}$ arising from so-called "hindered" water molecules in the matrix that form a complex with silicon tetrafluoride [14], as well as in the intensity of the band at $1593.1 \mathrm{~cm}^{-1}$ assigned to vibrations of the water molecules (acting as a proton acceptor) in the dimer [14]. The intensity of the band at $1610.5 \mathrm{~cm}^{-1}$ due to water molecules acting as proton donors is concurrently increased. In the region of the $v_{3}$ antisymmetric water stretches $\left(3500-3700 \mathrm{~cm}^{-1}\right)$, new bands are observed at 3641.9 and $3638.2 \mathrm{~cm}^{-1}$. In the region of the $v_{1}$ mode (symmetric stretching vibrations) of water, major changes are observed in the range $3750-3705 \mathrm{~cm}^{-1}$ : weak bands appear at 3723.1 

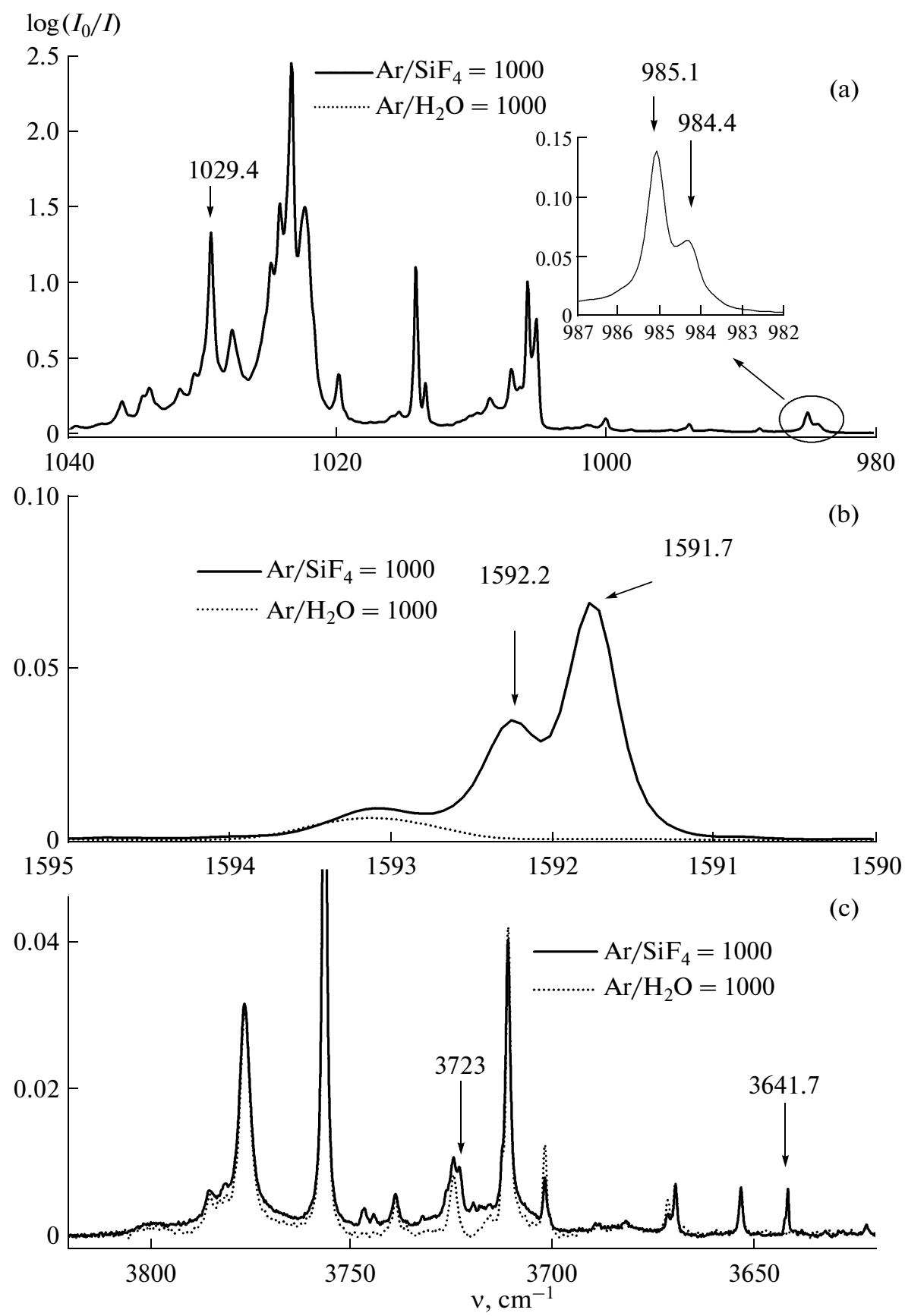

Fig. 1. Vibrational spectra of (a) $\mathrm{Ar} / \mathrm{SiF}_{4}=1000$ in the region of the $v_{3}$ mode of silicon tetrafluoride, (b) $\mathrm{Ar} / \mathrm{SiF} \mathrm{F}_{4}=1000$ and $\mathrm{Ar} / \mathrm{H}_{2} \mathrm{O}=1000$ in the region of the $v_{2}$ mode of water, (c) $\mathrm{Ar} / \mathrm{SiF}_{4}=1000$ and $\mathrm{Ar} / \mathrm{H}_{2} \mathrm{O}=1000$ in the region of the $v_{1}$ and $v_{3}$ modes of water (hereinafter, see Experimental for spectrum recording details).

and $3721.0 \mathrm{~cm}^{-1}$. The simultaneously appearing band at $3708.2 \mathrm{~cm}^{-1}$ arises from the water dimer [14].

To obtain more detailed information of the above spectral features, we studied the spectra of silicon tetrafluoride-water mixtures at a lower dilution with argon (as a rule, $1: 500$ ).

Figure 3a shows the spectrum of $\mathrm{SiF}_{4} / \mathrm{Ar}=500$ together with the spectra of $\mathrm{Ar} /\left(\mathrm{SiF}_{4} 51.8 \mathrm{mbar}+\mathrm{H}_{2} \mathrm{O}\right.$ 22.0 mbar, sample 3) 1 and $16 \mathrm{~h}$ after mixing. In the range $820-880 \mathrm{~cm}^{-1}$, the intensities of the bands at $862.6,850.9,8.46 .8$, and $836.4 \mathrm{~cm}^{-1}$ increased in the course of reaction, the last band having a characteristic doublet contour like that observed for the weak band at $836.4 \mathrm{~cm}^{-1}$ in the spectrum of pure silicon tetrafluoride. The band at $985 \mathrm{~cm}^{-1}$ built up, while the low-frequency shoulder at $984.5 \mathrm{~cm}^{-1}$ became almost unobservable. In the range $1010-1020 \mathrm{~cm}^{-1}$, the new band at $1018.8 \mathrm{~cm}^{-1}$ appeared, and the band at 

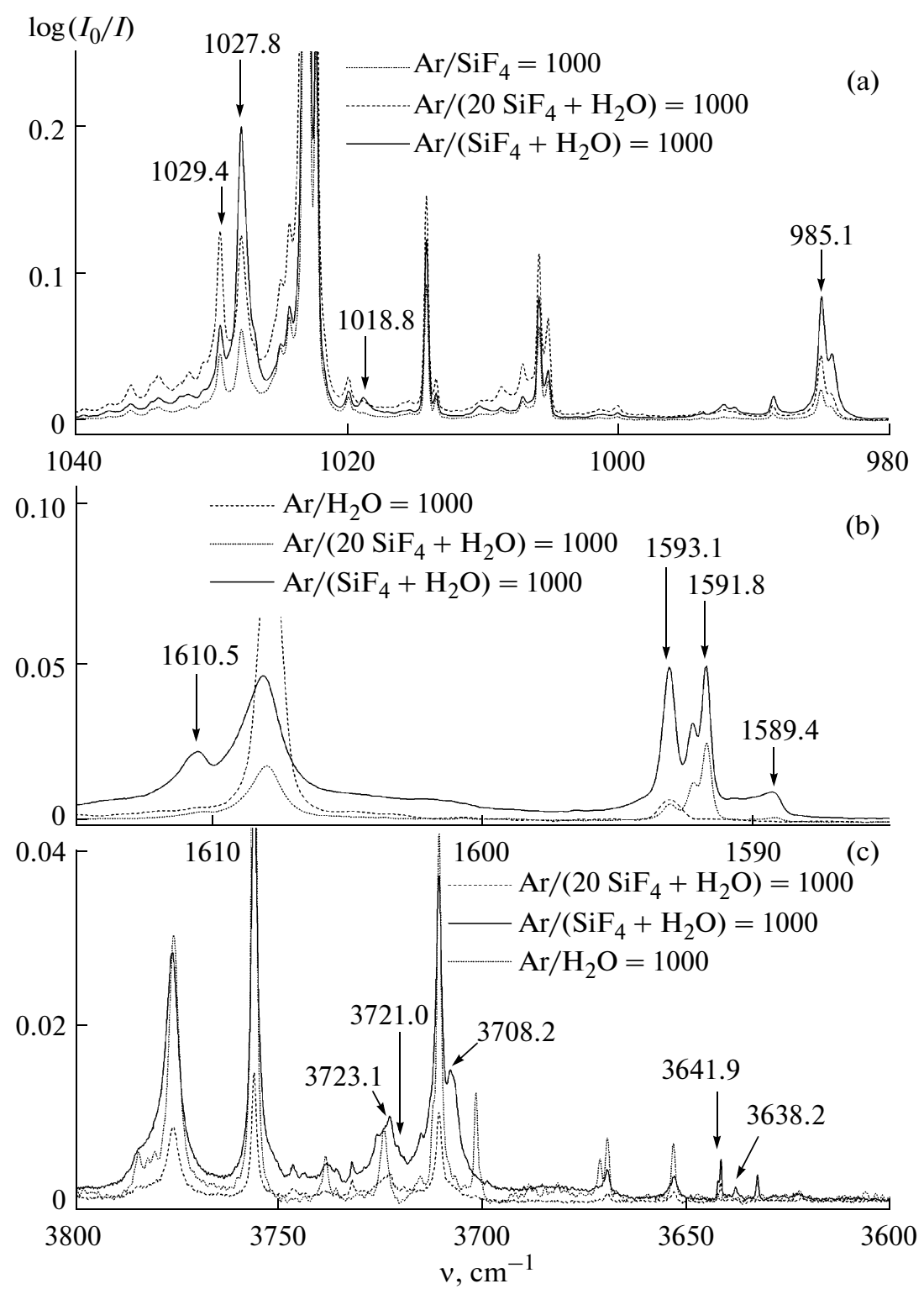

Fig. 2. Vibrational spectra of the systems $\mathrm{Ar} / \mathrm{SiF}_{4}=1000, \mathrm{Ar} /\left(\mathrm{SiF}_{4}+\mathrm{H}_{2} \mathrm{O}\right)=1000$, and $\mathrm{Ar} /\left(20 \mathrm{SiF}_{4}+\mathrm{H}_{2} \mathrm{O}\right)=1000$ in the region of (a) $v_{3}$ of silicon tetrafluoride, ( $v_{2}$ of water, and $v_{1}$ and $v_{3}$ of water (hereinafter, see text for the concrete component ratios).

$1019.4 \mathrm{~cm}^{-1}$ was observed as the inflection between 1019.9 and $1018.8 \mathrm{~cm}^{-1}$. The relative intensity of the band at 1029.4 increased. The intensity of the broad band with separate peaks in the range $1160-1280 \mathrm{~cm}^{-1}$ increased only slightly: even after a $16-\mathrm{h}$ reaction period, it differed insignificantly from the band in the spectrum of initial silicon tetrafluoride. In the region of water bending vibrations $\left(1560-1660 \mathrm{~cm}^{-1}\right)$ for the same mixture as in Fig. 3, the band with four maxima at $1600 \mathrm{~cm}^{-1}$ (Fig. 4a) became stronger (Fig. 4a). In the region of symmetric water stretches $3500-3700 \mathrm{~cm}^{-1}$ (Fig. 4b) the intensity of the bands at 3642, 3638.2, and $3628 \mathrm{~cm}^{-1}$ increased; in the region of antisymmetric vibrations $3700-3820 \mathrm{~cm}^{-1}$, the intensity of the band with maxima between 3723.2 and $3715.7 \mathrm{~cm}^{-1}$ became noticeably stronger.

The table summarizes the new lines and bands related to the silicon tetrafluoride-water interaction. It follows from these data that the structure of the bands at 1030 and $3760 \mathrm{~cm}^{-1}$, as well as at 830,1240 , and $1600 \mathrm{~cm}^{-1}$, in the spectra of silicon tetrafluoride and its mixtures with water, their relative intensities, and intensities of separate lines within each band depend in a rather complicated manner on the prehistory of a sample, the component ratio, and reaction duration. Nevertheless, these bands were assigned (table) on the basis of the previous quantum-chemical calculations of the thermodynamics and kinetics of 


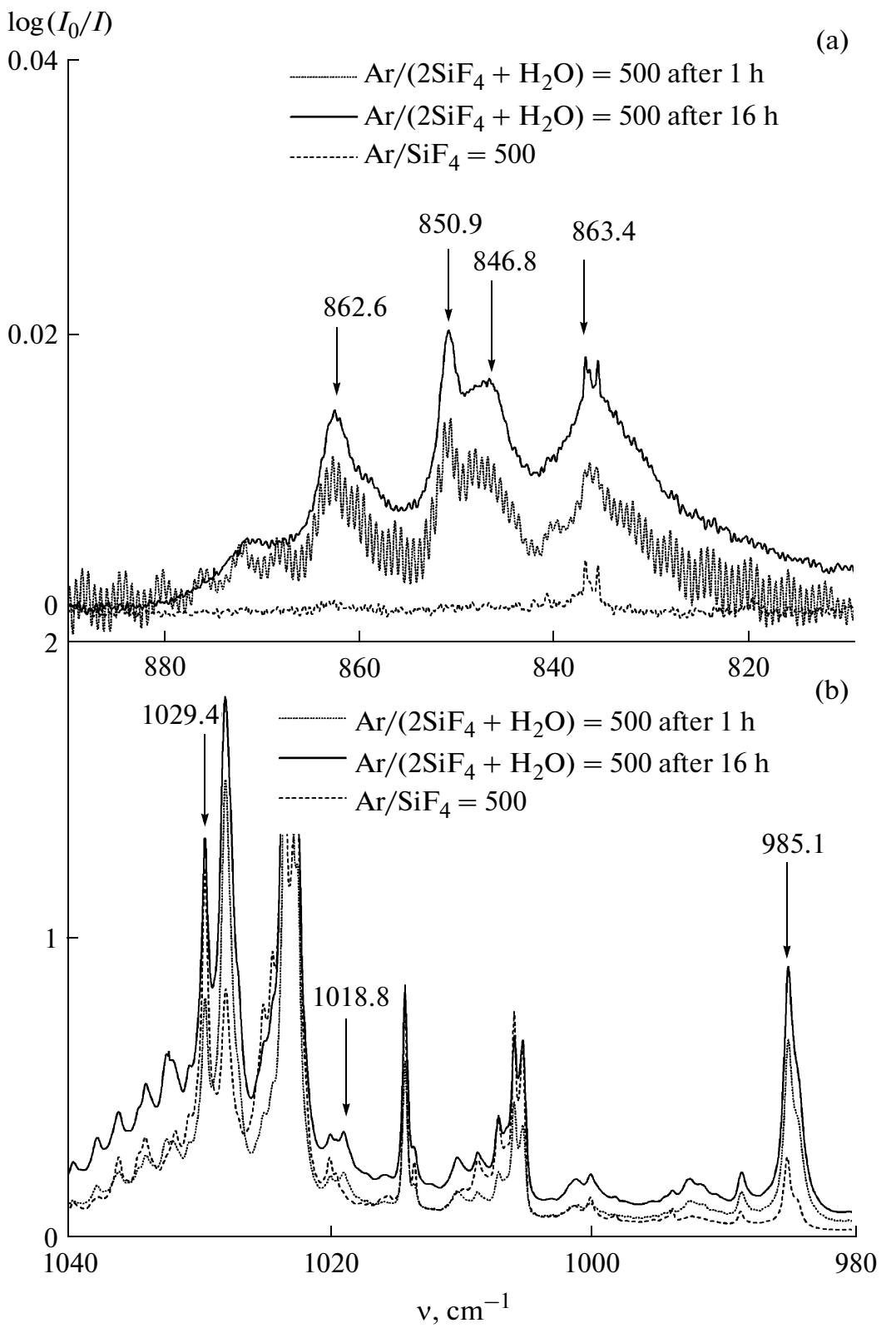

Fig. 3. Vibrational spectra of the $\mathrm{Ar} /\left(\mathrm{SiF}_{4}+\mathrm{H}_{2} \mathrm{O}\right)=500$ system 1 and $16 \mathrm{~h}$ after the mixing of the components (a) in the range $890-810 \mathrm{~cm}^{-1}$ and (b) in the region of $\mathrm{v}_{3}$ of silicon tetrafluoride.

the silicon tetrafluoride reaction with water and the IR spectra of major products $[6,9,10]$ and the results of studying their experimental spectra in the gas phase [4, $5,7,8]$ and in a low-temperature matrix $[12,13]$. Once the components have been mixed, it takes much shorter time for them to interact than the time of recording the IR spectrum. Among the reaction products, the molecular complex of the donor-acceptor type $\mathrm{F}_{4} \mathrm{Si} . . . \mathrm{OH}_{2}$ is noteworthy. The $\mathrm{Si}-\mathrm{F}$ vibration in this complex gives rise to strong $\left(985.1-984.4 \mathrm{~cm}^{-1}\right)$ and weaker doublets $\left(992.5-991.6 \mathrm{~cm}^{-1}\right)$ due to vibrations of the same type. They split due to the matrix effect. A characteristic feature of chemical interaction in this system is the appearance of new bands at 1019.4 and $1018.8 \mathrm{~cm}^{-1}$ assigned to the natural vibrations $\mathrm{ofSiF}_{4}$ in this region [13]. The former band is detected either when the matrix concentration is increased at a constant component ratio or when a mixture is kept for a rather long time before deposition. According to the experimental $[4,7,8]$ and computational [10] data, SI-F vibrations with an admixture of $\mathrm{Si}-\mathrm{O}$ vibrations of $\mathrm{Si}_{2} \mathrm{~F}_{6} \mathrm{O}$ and $\mathrm{SiF}_{3} \mathrm{OH}$ molecules can be observed in this range. According to [9], formation of hexafluorodisiloxane is thermodynamically somewhat more favorable, whereas the energy barrier is lower for trifluorosilanol. Therefore, we can suggest that the 


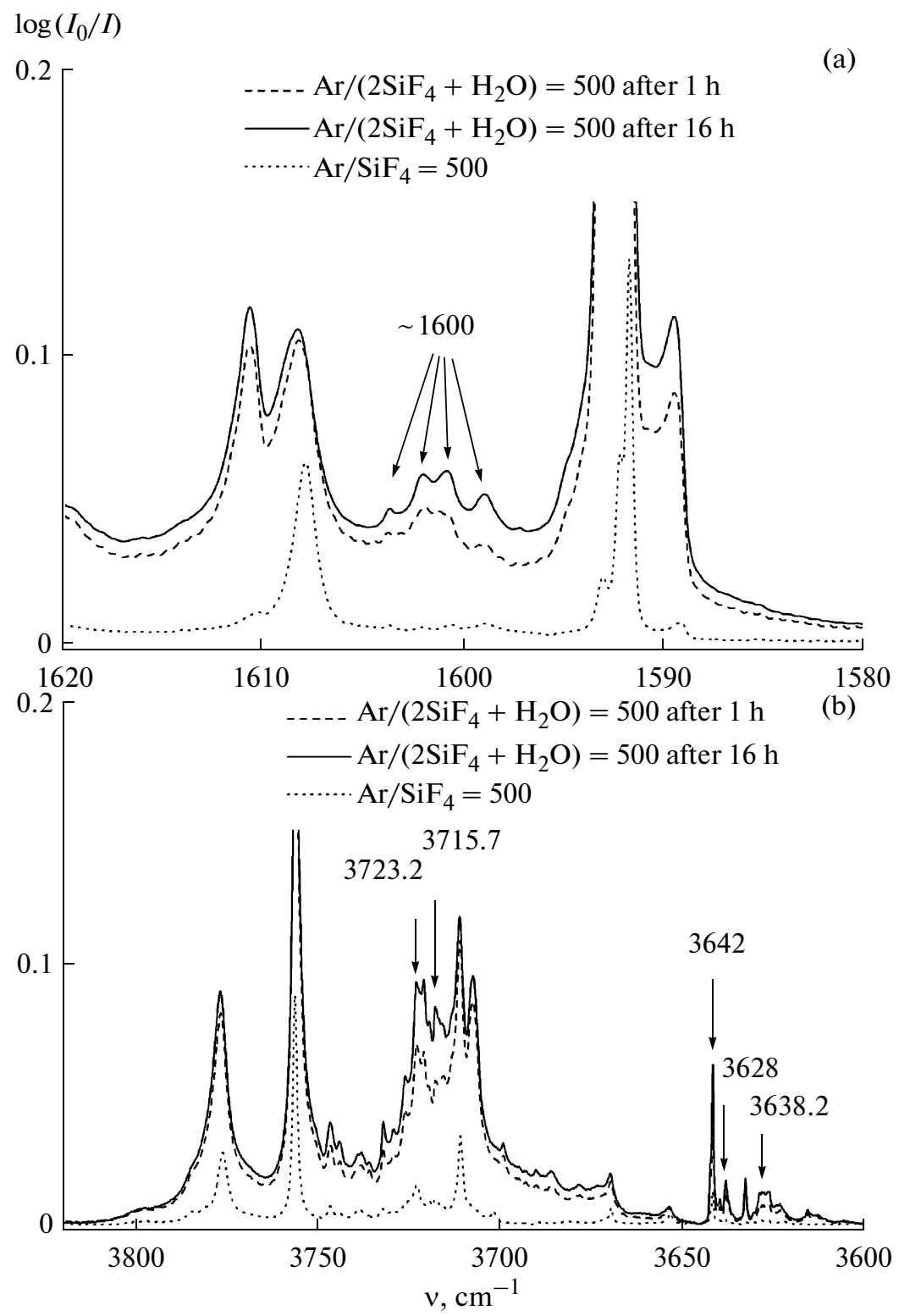

Fig. 4. Vibrational spectra of the $\mathrm{Ar} /\left(\mathrm{SiF}_{4}+\mathrm{H}_{2} \mathrm{O}\right)=500$ system 1 and $16 \mathrm{~h}$ after the mixing of the components in the region of (a) $v_{2}$ of water and (b) $v_{1}$ and $v_{3}$ of water.

band at $1018.8 \mathrm{~cm}^{-1}$ is due to $\mathrm{SiF}_{3} \mathrm{OH} 3 \mathrm{OH}$ molecules; in addition, the spectrum also shows the band with peaks at $862.6,850.9,846.8$, and $836.4 \mathrm{~cm}^{-1}$, which is absent (except a very weak peak at $836.4 \mathrm{~cm}^{-1}$ ) in the spectrum of initial silicon tetrafluoride. Calculations predict that this range should contain the band of $\mathrm{Si}-$ $\mathrm{O}-\mathrm{H}$ bending vibrations of the $\mathrm{SiF}_{3} \mathrm{OH}$ molecule and the band of the difference between symmetric vibrations of twoSiF $\mathrm{F}_{3}$ moieties of the $\mathrm{Si}_{2} \mathrm{~F}_{6} \mathrm{O}$ molecule, the intensity of the latter being approximately twice as low as the intensity of the former. It is worth noting that the strong (according to calculations) antisymmetric $\mathrm{F}-$ $\mathrm{Si}-\mathrm{F}$ vibration band is near $980 \mathrm{~cm}^{-1}$ and can be overlapped with the band of the complex at $985 \mathrm{~cm}^{-1}$ (this can be responsible for the disappearance of the low- frequency shoulder at this band in the spectrum of initial silicon tetrafluoride on adding water to it).

The $\mathrm{Si}-\mathrm{O}-\mathrm{Si}$ antisymmetric vibration band for the $\mathrm{Si}_{2} \mathrm{~F}_{6} \mathrm{O}$ molecule in the gas phase is observed at $1190-1260 \mathrm{~cm}^{-1}$ [8]. According to calculations, this band is the strongest one in the spectra of both molecules; however, because of a very large half-width and complex shape, its experimentally observed intensity is low. Nevertheless, we can state that the highest intensity of this band is achieved when the bands at 1019.4 and $836.4 \mathrm{~cm}^{-1}$ are simultaneously present in the spectrum. Calculations predict that the band at $1019.4 \mathrm{~cm}^{-1}$ should by $1.5-2$ times as weak as the band at $1018.8 \mathrm{~cm}^{-1}$ of trifluorosilanol and should be observed in the spectrum of initialSiF 4 only with an increase in 
Positions of the bands due to the products of the SiF@4 reaction with water in the IR spectrum in the argon matrix at $14 \mathrm{~K}$ and their assignment

\begin{tabular}{|c|c|c|}
\hline$v_{\max }, \mathrm{cm}^{-1}$ & Assignment $([10]$ except $*$ and $* *)$ & Intensity, $\mathrm{km} / \mathrm{mol}[10]$ \\
\hline 836.1 & $v_{s}\left(\mathrm{~F}_{3} \mathrm{Si}\right)-v_{s}\left(\mathrm{SiF}_{3}\right)$ of the $\mathrm{Si}_{2} \mathrm{~F}_{6} \mathrm{O}$ molecule & 96 \\
\hline $\begin{array}{l}848.1 \\
851.38 \\
862.5\end{array}$ & $v_{s}\left(\mathrm{~F}_{3} \mathrm{Si}\right)+v(\mathrm{Si}-\mathrm{O})+\delta(\mathrm{H}-\mathrm{O}-\mathrm{Si})$ of the $\mathrm{SiF}_{3} \mathrm{OH}$ molecule & 186 \\
\hline $\begin{array}{l}984.4 \\
985.1\end{array}$ & $v_{a s}(\mathrm{~F}-\mathrm{Si}-\mathrm{F})$ in the complex with $\mathrm{H}_{2} \mathrm{O}+\mathrm{v}_{a s}(\mathrm{~F}-\mathrm{Si}-\mathrm{F})$ of the $\mathrm{SiF}_{3} \mathrm{OH}$ molecule (?) & 265 \\
\hline 1018.8 & $v_{a s}\left(\mathrm{~F}_{3} \mathrm{Si}\right)+v(\mathrm{Si}-\mathrm{O})$ of the $\mathrm{SiF}_{3} \mathrm{OH}$ molecule & 228 \\
\hline 1019.4 & $v_{a s}\left(\mathrm{~F}_{3} \mathrm{Si}\right)+v_{a s}\left(\mathrm{~F}_{3} \mathrm{Si}\right)+v_{s}(\mathrm{Si}-\mathrm{O}-\mathrm{Si})$ of the $\mathrm{Si}_{2} \mathrm{~F}_{6} \mathrm{O}$ molecule & 34 \\
\hline $\begin{array}{l}1212.6 \\
1224.0 \\
1232.4 \\
1244.8 \\
1255.5 \\
1268.2 \\
1276.6\end{array}$ & $v_{a s}(\mathrm{Si}-\mathrm{O}-\mathrm{Si})$ of the $\mathrm{Si}_{2} \mathrm{~F}_{6} \mathrm{O}$ molecule & 692 \\
\hline 1601.5 & $\delta(\mathrm{H}-\mathrm{O}-\mathrm{H})$ in the complex with $\mathrm{SiF}_{4}$ & 80 \\
\hline $3554.6 *$ & $v(\mathrm{H}-\mathrm{F})$ in the $\mathrm{HF}$ complex with $\mathrm{H}_{2} \mathrm{O}[19-21]$ & - \\
\hline $\begin{array}{l}3628.0 \\
3638.2 \\
3642.2\end{array}$ & $v_{s}(\mathrm{H}-\mathrm{O}-\mathrm{H})$ in the $\mathrm{HF}$ complex with $\mathrm{SiF}_{4}$ & 23 \\
\hline $\begin{array}{l}3717.5 \\
3721.2\end{array}$ & $v_{a s}(\mathrm{O}-\mathrm{H})$ of the $\mathrm{SiF}_{3} \mathrm{OH}$ molecule & 128 \\
\hline $\begin{array}{l}3723.4 \\
3726.4 \\
3732.6\end{array}$ & $v_{a s}(\mathrm{H}-\mathrm{O}-\mathrm{H})$ in the complex with $\mathrm{SiF}_{4}$ & 86 \\
\hline $\begin{array}{l}3887.2 * * \\
3967.1\end{array}$ & $v(\mathrm{H}-\mathrm{F})$ in the $\mathrm{HF}$ complex with $\mathrm{SiF}_{4}[18-20]$ & - \\
\hline
\end{tabular}

the matrix concentration (on going from the dilution 1000 to 500$)$.

Characteristic changes in the spectral ranges 1600 and $3500-3800 \mathrm{~cm}^{-1}$ observed on adding water to silicon tetrafluoride should be caused only by the formation of the complex and trifluorosilanol. These changes are clearly seen in Figs. 2 and 4 related to various matrix concentrations and reaction times. As is seen, with an increase in the reaction duration, the intensity of the band at $1602 \mathrm{~cm}^{-1}$ increases, whereas an increase in the matrix concentration leads to the shift of this band to $1599 \mathrm{~cm}^{-1}$. This is likely associated with a change in the structure of the $\mathrm{SiF}_{4}$-water complex since the above band was assigned to the bending vibrations of the water molecule in this complex [12]. In the region of the $v_{3}$ antisymmetric mode of water molecules, new bands are observed at 3642.2, 3638.2, and $3628.0 \mathrm{~cm}^{-1}$, which can be detected (especially the first one) even in the spectrum of initial silicon tetrafluoride. In the region of the $v_{1}$ antisymmetric mode of water, an increase in the water content in a mixture or an increase in the reaction time leads to the appear- ance and buildup of the band with peaks at 3762.6 , $3726.4,3723.4$, and $3721.2 \mathrm{~cm}^{-1}$. Its component at $3722 \mathrm{~cm}^{-1}$ was assigned in [12] to antisymmetric stretches of the water molecule in the complex. With an increase in the matrix concentration, the spectrum is dominated by the band at $3717 \mathrm{~cm}^{-1}$, which was previously almost unobservable due to the low absorptance, and the considerably weaker band at $3732.6 \mathrm{~cm}^{-1}$. In our opinion, this band arises from $\mathrm{O}-\mathrm{H}$ bond vibrations in the $\mathrm{SiF}_{3} \mathrm{OH}$ molecule or in more complicated fluorosilanols. This band is centered at $3760 \mathrm{~cm}^{-1}$ in the spectrum of the gas phase [4] and at $3685 \mathrm{~cm}^{-1}$ in a carbon tetrachloride solution [6].

Our results allow us to give the following interpretation of the water-induced impurity absorption in the spectra of $\mathrm{SiF}_{4}$ in the gas phase at a pressure of several hundreds of torrs and in the matrix at a rather high dilution. The water admixture contained in silicon tetrafluoride partially reacts with the host compound, and under equilibrium conditions, hexafluorodisiloxane predominates in the system (the bands at 836.4 and $1019.4 \mathrm{~cm}^{-1}$ and the broad band with several peaks 
in the range $1200-1260 \mathrm{~cm}^{-1}$ in the matrix; the band at $840 \mathrm{~cm}^{-1}$ and the broad band at $1200-1300 \mathrm{~cm}^{-1}$ in the gas phase). The presence of the trifluorosilanol admixture in the equilibrium system is betrayed in some cases by the inflection at $1018.4 \mathrm{~cm}^{-1}$ in the lowfrequency wing of the band at $1020 \mathrm{~cm}^{-1}$ and the weak absorption at $3717 \mathrm{~cm}^{-1}$ in the matrix and by the very weak band at $3762 \mathrm{~cm}^{-1}$ in the gas phase, which is, as a rule, unobservable at low water contents. Under matrix isolation conditions, some water molecules remain bound to silicon tetrafluoride in the complex, which is indicated by the bands at 985 and $1602 \mathrm{~cm}^{-1}$ and the typical redistribution of the water band intensities in this region, as well as by the absorption at $3642.2,36.38 .2$, and $3628.0 \mathrm{~cm}^{-1}$ in the region of the $v_{3}$ antisymmetric mode of water molecules and at 3732.6, $3726.4,3732.4$, and $3721.2 \mathrm{~cm}^{-1}$ in the region of the $v_{1}$ symmetric mode of water molecules.

One of the products of the silicon tetrafluoride hydrolysis is hydrogen fluoride, which gives rise to rather weak narrow absorption bands at $3920-3970 \mathrm{~cm}^{-1}$ in the matrix spectrum. Self-association or complexation with other molecules leads to broadening of these bands and to their shift toward lower frequencies down to $3500 \mathrm{~cm}^{-1}$ [18]. For all water-containing systems, we observed extremely weak bands at 3967,3877 , and $3554.6 \mathrm{~cm}^{-1}$, which are presumably due to the absorption of $\mathrm{HF}$ in different environments. The first two bands can arise from hydrogen fluoride bound toSiF 4 in a weak complex since they are close to the bands observed for similar complexes with $\mathrm{WF}_{6}$ and $\mathrm{MoF}_{6}$ [19]. The band at $3554.6 \mathrm{~cm}^{-1}$ coincides with the strongest band observed in the spectrum of the HF complex with water in the argon matrix [20]. It should be taken into account that hydrogen fluoride is rather prone to adsorption on the equipment walls. In the experiments on studying the $\mathrm{SiF}_{4}$ hydrolysis in the gas phase at a pressure of several hundreds of millibars, the absorption bands of the nascent hydrogen fluoride are rather strong.

Thus, the FTIR absorption spectra of silicon tetrafluoride with water additions in the argon matrix at $14 \mathrm{~K}$ were studied at different component ratios and reaction times before the moment of matrix formation. New lines and bands were detected in the ranges $820-1200,1600$, and $3700-3900 \mathrm{~cm}^{-1}$ that arise from the products of partial hydrolysis ofSiF 4 . Invoking the results of earlier experiments in the gas phase and quantum-chemical calculations of the intensities of $\mathrm{SiF}_{3} \mathrm{OH}, \mathrm{Si}_{2} \mathrm{~F}_{6} \mathrm{O}$, and $\mathrm{F}_{4} \mathrm{Si} . . . \mathrm{OH}_{2}$ modes, we showed that, over a period of time much shorter than the spectrum recording time, silicon tetrafluoride reacts with water to form the $1: 1$ donor-acceptor complex and trifluorosilanol, which later partially converts into hexafluorodisiloxane $\mathrm{SiF}_{3} \mathrm{OH}$. The latter two products are also stable in the gas phase and can be detected as impurities in silicon tetrafluoride.

\section{ACKNOWLEDGMENTS}

This work was supported by Program no. 2 of the Division of Chemistry and Materials Science of the RAS, the German Academic Exchange Service (DAAD, ref. 325-2008), the International Science and Technology Center (project no. 3736), and the Russian Foundation for Basic Research (project nos. 08-07-00318ba and 08-08-12076 ofi).

\section{REFERENCES}

1. H. E. Ulmer, D. Pickens, F. J. Rahl, and P. A. Lefrancois, US Patent 4407 783, 1983.

2. S. Kasouit, J. Damon-Lacoste, and R. Vanderhaghen, J. Non-Cryst. Solids 338-340, 86 (2004).

3. A. V. Loginov and A. M. Garbar, Vysokochist. Veshchestva, No. 5, 27 (1989).

4. P. G. Chuprov, K. G. Sennikov, S. K. Tokhadze, et al., Neorg. Mater. 42 (8), 1017 (2006) [Inorg. Mater. 42 (8), 924 (2006)].

5. J. L. Margrave, K. G. Sharp, and R. W. Wilson, J. Am. Chem. Soc. 92 (6), 1530 (1970).

6. P. G. Sennikov, M. A. Ikrin, S. K. Ignatov, et al., Izv. Akad. Nauk, Ser. Khim., No. 1, 92 (1999).

7. W. D. Reents, Jr., D. L. Wood, and A. M. Mujsce, Anal. Chem. 57 (1), 104 (1985).

8. J. R. Durig, V. F. Kalasinsky, and M. J. Flanagan, Inorg. Chem. 14 (11), 2839 (1975).

9. S. K. Ignatov, P. G. Sennikov, B. S. Ault, et al.,J. Phys. Chem. A 103 (41), 8328 (1999).

10. S. K. Ignatov, P. G. Sennikov, L. A. Chuprov, and A. G. Razuvaev, Izv. Akad. Nauk, Ser. Khim., No. 4, 797 (2003).

11. A. P. Burtsev, V. N. Bocharov, S. K. Ignatov, et al., Opt. Spektrosk. 98 (2), 261 (2005) [Opt. Spectrosc. 98 (2), 227 (2005)].

12. B. S. Ault, J. Am. Chem. Soc. 105 (18), 5742 (1983).

13. S. K. Ignatov, T. D. Kolomiitsova, Z. Mielke, et al., Chem. Phys. 324, 753 (2006).

14. A. Engdahl and B. Nelander, J. Mol. Struct. 193, 101 (1989).

15. S. Hirabayashi and K. M. T. Yamada, Chem. Phys. Lett. 418, 323 (2006).

16. A. Olbert-Majkut, Z. Mielke, and K. G. Tokhadze, Chem. Phys. 280, 211 (2002).

17. M. Mucha and Z. Mielke, J. Phys. Chem. A 111 (12), 2398 (2007).

18. L. Andrews, J. Phys. Chem. 88 (14), 2940 (1984).

19. R. D. Hunt, L. Andrews, and L. Mac Toth, J. Phys. Chem. 95 (3), 1183 (1991).

20. L. Andrews and G. L. Johnson, J. Chem. Phys. 79 (8), 3670 (1983).

SPELL: 1. polycrystalline 